\title{
Why homosexuality is a risk factor for eating disorders in males
}

Citation for published version (APA):

Hospers, H. J., \& Jansen, A. T. M. (2005). Why homosexuality is a risk factor for eating disorders in males. Journal of Social and Clinical Psychology, 24(8), 1188-1201.

https://doi.org/10.1521/jscp.2005.24.8.1188

Document status and date:

Published: 01/01/2005

DOI:

10.1521/jscp.2005.24.8.1188

Document Version:

Publisher's PDF, also known as Version of record

Document license:

Taverne

Please check the document version of this publication:

- A submitted manuscript is the version of the article upon submission and before peer-review. There can be important differences between the submitted version and the official published version of record.

People interested in the research are advised to contact the author for the final version of the publication, or visit the DOI to the publisher's website.

- The final author version and the galley proof are versions of the publication after peer review.

- The final published version features the final layout of the paper including the volume, issue and page numbers.

Link to publication

\footnotetext{
General rights rights.

- You may freely distribute the URL identifying the publication in the public portal. please follow below link for the End User Agreement:

www.umlib.nl/taverne-license

Take down policy

If you believe that this document breaches copyright please contact us at:

repository@maastrichtuniversity.nl

providing details and we will investigate your claim.
}

Copyright and moral rights for the publications made accessible in the public portal are retained by the authors and/or other copyright owners and it is a condition of accessing publications that users recognise and abide by the legal requirements associated with these

- Users may download and print one copy of any publication from the public portal for the purpose of private study or research.

- You may not further distribute the material or use it for any profit-making activity or commercial gain

If the publication is distributed under the terms of Article $25 \mathrm{fa}$ of the Dutch Copyright Act, indicated by the "Taverne" license above, 


\title{
WHY HOMOSEXUALITY IS A RISK FACTOR FOR EATING DISORDERS IN MALES
}

\author{
HARM J. HOSPERS AND ANITA JANSEN \\ Maastricht University, The Netherlands
}

There is a typical overrepresentation of homosexual males in clinical eating disorder samples. The present study investigated the role of gender role orientation, peer pressure, self-esteem, and body dissatisfaction in relation to eating disorder symptoms among a sample of homosexual men and a sample of heterosexual men. The results show that most variables were highly interrelated. However, using multivariate regression analyses it was found that body dissatisfaction, and not self-esteem, was the dominant predictor of eating disorder symptoms. For both heterosexual and homosexual men, a higher level of body dissatisfaction was related to higher Body Mass Index (BMI), more peer pressure, and lower masculinity scores. In addition, an interaction of sexual orientation and peer pressure was found: the relationship between peer pressure and body dissatisfaction was substantially more pronounced among homosexual men. Finally, associations between eating disorder symptoms on the one hand and sexual orientation, gender role orientation and peer pressure on the other hand, became non-significant when taking body dissatisfaction into account. The results show the central role of body dissatisfaction in the relationship between homosexuality and eating disorder symptoms, as well as the contribution of peer pressure. Directions for future research are discussed.

A consistent finding in Western countries is that homosexual men are more vulnerable to eating disorders than heterosexual men. Amongst homosexual males eating disorders and disordered eating attitudes are significantly more prevalent than amongst heterosexual men (Andersen, 1999; Brand, Rothblum, \& Solomon, 1992; Harvey \& Robin-

Thanks are expressed to L. Bour, L. Buskens, M. Denolf, R. Drijgers, I. Eerdekens, M. Heijmans, H. Jossberger, and R. Martens for the data collection, to J. Winants and J. Beursgens for their help with constructing the internet questionnaire, and to www.expreszo.nl for hosting our questionnaire on their website. We also wish to thank the anonymous reviewers for their insightful comments.

Address correspondence to Harm J. Hospers, Maastricht University, Faculty of Psychology, Department of Experimental Psychology. PO Box 616, 6200 MD Maastricht, The Netherlands; E-mail: h.hospers@psychology.unimaas.nl. 
son, 2003; Lakkis, Ricciardelli, \& Williams, 1999; Moore \& Keel, 2002; Strong, Williamson, Netemeyer, \& Geer, 2000; Williamson \& Hartley, 1998; Yelland \& Tiggemann, 2003, but see Boroughs \& Thompson, 2002). In addition there is a typical overrepresentation of homosexual males in clinical eating disorder samples: an average of 20\% (Andersen, 1999) to $42 \%$ (Russell \& Keel, 2002) of males with eating disorders are homosexual. A most relevant question is: why is homosexuality a risk factor for eating disorders in males?

Several ideas have been put forward to explain why male homosexuality contributes specifically to risk for eating disorders, and the most wide-spread theory is that body dissatisfaction is the critical variable that makes homosexual men vulnerable to disordered eating (Boroughs \& Thompson, 2002). Body dissatisfaction is defined as the negative subjective evaluation of one's physical body such as figure and weight, and has been found to be a prominent risk factor in the development and maintenance of eating disorders (Stice \& Shaw, 2002). Indeed, homosexual men show higher rates of body dissatisfaction than heterosexual man (Russel \& Keel, 2002; Strong, Singh, \& Randall, 2000). The body dissatisfaction in homosexual males is somewhat different from the body dissatisfaction in females; it involves weight as well as muscularity. Whereas the female beauty ideal is primarily slim, the male homosexual ideal is not only being slim, but also being muscular (Yelland \& Tiggemann, 2003).

Dissatisfaction with one's body is considered to follow mainly from socio-cultural pressures to be thin (Stice, Maxfield, \& Wells, 2003; Stice \& Shaw, 2002). The increased pressure in the gay community to reach the ideal male figure is supposed to increase body concerns and body dissatisfaction in homosexual men (Harvey \& Robinson, 2003; Williamson \& Hartley, 1998), which in turn is supposed to foster disordered eating attitudes and behaviors (Yelland \& Tiggemann, 2003).

Some authors state that it is not primarily sexual orientation but femininity that is associated with higher levels of eating disorders, whereas masculinity has been associated with lower levels (Lakkis et al., 1999; Meyer, Blissett, \& Oldfield, 2001; Murnen \& Smolak, 1997; Strong et al., 2000), thus femininity (in males and females) being a risk factor and masculinity being a protective factor in eating disorders. Femininity is supposed to be linked to eating disorders because the feminine role orientation in western society is associated with a greater focus on appearance. Although homosexual males score lower on measures of masculinity than heterosexual males and higher on measures of femininity (Meyer et al., 2001; Strong et al., 2000), sexual orientation does not necessarily parallel masculinity / femininity: some homosexual men are relatively masculine and others are relatively feminine. Russel and Keel (2002) for exam- 
ple, did not find increased femininity in homosexual men. Differences in gender role orientation (masculinity/femininity) might account for differences in body dissatisfaction; feminine men (homosexual as well as heterosexual) might experience a conflict between their feminine role orientation and the society's view of men as physically strong and masculine (Strong et al., 2000).

Low self-esteem has also been related to eating disorders (Cervera, Lahortiga, Martínez-González, Gual, de Irala-Estévez, \& Alonso, 2003; Gual, Pérez-Gaspar, Martínez-González, Lahortiga, de Irala-Estévez, \& Cervera-Enguix, 2002). Williamson (Williamson, 1999; Williamson \& Hartley, 1998) argues that internalized "homonegativity" — defined as hostility and prejudice against the homosexual males-affects the self-esteem of homosexuals, and that it is their low self-esteem that is critical in the origin of eating disorders. Yelland and Tiggemann (2003) argue that body dissatisfaction in homosexual men might have a negative impact on the homosexual men's feelings of self-worth. They found a significant lower self-esteem in homosexual men, and suggest that it is the experienced pressure from within the homosexual community to be attractive and muscular, that lowers their self-esteem.

In sum, several key variables have been associated with eating disorders in homosexual males: higher femininity and lower masculinity, and peer pressure to be thin and muscular are hypothesized to decrease self-esteem and increase body dissatisfaction. The decreased self-esteem and increased body dissatisfaction add to eating disorder symptoms.

In the present study it was hypothesized that (1) increased body dissatisfaction and decreased self-esteem are related to increased levels of eating disorder symptoms, that (2) self-esteem and body dissatisfaction are dependent upon peer pressure and gender role orientation, and that these relationships are more pronounced in homosexual men, and finally that (3) relations between sexual orientation, peer pressure, and gender role orientation on the one hand and eating disorder symptoms on the other hand are mediated by body dissatisfaction and self-esteem.

\section{METHOD}

\section{SUBJECTS}

This study used two strategies to recruit subjects. First, a banner was placed on the homepage of the most popular Dutch website for young gay and bisexual men and women (www.expreszo.nl). The banner asked visitors to participate in a study from Maastricht University on ap- 
pearance and eating behavior. By clicking the banner potential subjects were redirected to a webpage on the university server that introduced the current study. Those interested in participating in the study could start the online questionnaire by clicking a link on this page. After completion, the questionnaire could be anonymously submitted to the researchers. Second, male students were approached at university buildings and at a college for vocational training. They were asked to complete a paper questionnaire on appearance and eating behavior, or were given the address of the webpage where the introduction of the study and the link to the online questionnaire could be found.

\section{QUESTIONNAIRE}

Respondents were first asked for their age and gender. Educational level was measured by the nine Dutch school levels, ranging from primary school to university. The answers were recoded into three categories, reflecting a low, medium, and high educational level. Sexual orientation was measured by asking "To who are you sexually attracted?" with the answering options: exclusively to men, mostly to men, to both men and women, mostly to women, and exclusively to women. Subsequently, respondents were asked to provide their body height in centimeters and their current body weight in kilos.

The next section of the questionnaire comprised the following scales:

Eating Disorder Symptoms. Eating Disorder Symptoms were measured using the Eating Disorder Examination Questionnaire (EDE-Q; Fairburn \& Beglin, 1994). The EDE-Q is a validated self-report questionnaire, consisting of 30 items. Seven items pertaining to binge eating were excluded since recent research has shown that self-reported binge eating tends to be unreliable (Fairburn \& Beglin, 1994; Kalarchian, Wilson, Brolin, \& Bradley, 2000; Wilfley, Schwartz, Spurrell, \& Fairburn, 1997). The remaining four EDE-Q subscales are: Restraint ( 5 items, $\alpha=.84$ ), Eating Concerns (5 items, $\alpha=.77$ ), Weight Concerns (5 items, $\alpha=.72$ ), and Shape Concerns ( 8 items, $\alpha=.88$ ). The EDE-Q global score is computed by adding the mean scores of these four subscales, divided by four. The scores of the EDE-Q subscales and the global score range from $0=$ absent to $6=$ highly present $/$ very severe (Cronbach's $\alpha=.89$ ).

Body Dissatisfaction. The 16-item Body Shape Questionnaire (BSQ; Cooper, Taylor, Cooper, \& Fairburn, 1987; 16-item version Evans \& Dolan, 1993) was used. A sample question is: "How often in the past four weeks have you been ashamed of your body?" Respondents answered each question on a 6 -point scale, ranging from $1=$ never, to $6=$ all the time. Cronbach's reliability was high $(\alpha=.90)$. A higher score on this scale indicates higher dissatisfaction with one's body. 
Self-Esteem. Self-Esteem was measured by Rosenberg's Self-Esteem scale (RSE; Rosenberg, 1965). This scale consists of 10 items with a 4 -point answering scale ( $1=$ totally disagree, $4=$ totally agree). The total score can range from 10 (lowest self-esteem) to 40 (highest self-esteem). Cronbach's $\alpha$ was .88 .

Masculinity and Femininity. Masculinity and Femininity were measured using the Bem Sex Role Inventory (BSRI; Bem, 1974). The BSRI consists of 10 items measuring masculine traits, 10 items measuring feminine traits, and 10 neutral traits. Chung (1996) reports good scale validity for both heterosexual and gay men. Each item is scored on a 7-point scale $(1=$ never present, $7=$ always present $)$. Both the masculinity and the femininity score can range from 10 to 70 . Cronbach's $\alpha$ was .77 for the masculinity scale and .81 for the femininity scale.

Peer Pressure. This scale was designed by the authors. The concept was operationalized by asking the extent to which friends of respondents value beauty, appearance, slenderness, muscularity and the like (nine statements, range; $1=$ completely disagree, $7=$ completely agree). An example item is "My friends think it is important to be slender." The total score can range from 9 to 63 (Cronbach's $\alpha=.84$ ). The questions of this scale are included in the Appendix. A higher score indicates higher perceived peer pressure.

\section{RESULTS}

A total of 108 persons responded through the online questionnaire (85 male, 23 female). Only the data from the male respondents were included. Of these 85 males, 65 were mostly or exclusively attracted to men, 2 to men and women, and 18 mostly or exclusively to women. The paper questionnaire was completed by 156 men ( 5 mostly or exclusively attracted to men, 151 mostly or exclusively attracted to women). The two respondents who were attracted to both men and women were excluded from further analysis, leaving a total of 70 male respondents who were mostly or exclusively attracted to men (hereafter referred to as homosexual), and 169 male respondents mostly or exclusively attracted to women (hereafter referred to as heterosexual). Mean age of respondents was 23.0 years $(s d=3.7)$. Homosexual subjects were slightly older than heterosexual subjects (homosexuals: $M=24.0, s d=3.3$; heterosexuals: $M$ $=22.6$ years, $s d=3.8 ; F(237)=7.1, p<.01)$. Eighty percent had a high educational level, $19 \%$ a medium educational level, and $1 \%$ a low educational level. The educational level of homosexual men did not differ significantly from the heterosexual men $\left(\chi^{2}(2)=0.43, n s\right)$. There were no 
TABLE 1. Mean scores for homosexual and heterosexual respondents on BMI, and psychosocial variables of interest (standard deviations in parentheses).

\begin{tabular}{lrrrr}
\hline & $\begin{array}{r}\text { Heterosexual men } \\
(N=\mathbf{1 6 9})\end{array}$ & $\begin{array}{r}\text { Homosexual men } \\
(\boldsymbol{N}=\mathbf{7 0 )}\end{array}$ & $p<$ & $\begin{array}{r}\text { Total } \\
(\boldsymbol{N}=\mathbf{2 3 9 )}\end{array}$ \\
\hline BMI & $22.62(2.5)$ & $21.42(2.8)$ & .001 & $22.27(2.6)$ \\
EDE-Q Restraint & $0.40(0.8)$ & $0.76(1.0)$ & .01 & $0.51(0.9)$ \\
EDE-Q Weight concerns & $0.55(0.7)$ & $1.18(1.1)$ & .001 & $0.74(0.9)$ \\
EDE-Q Eating Concerns & $0.16(0.4)$ & $0.42(0.7)$ & .001 & $0.24(0.5)$ \\
EDE-Q Shape Concerns & $0.65(0.7)$ & $1.49(1.1)$ & .001 & $0.90(0.9)$ \\
EDE-Q Global & $0.44(0.5)$ & $0.96(0.9)$ & .01 & $0.59(0.7)$ \\
Body Dissatisfaction & $22.29(6.5)$ & $29.54(12.2)$ & .001 & $24.41(9.1)$ \\
Self-Esteem & $34.47(3.8)$ & $31.90(6.2)$ & .001 & $33.71(4.8)$ \\
Masculinity & $48.80(7.0)$ & $46.64(8.0)$ & .05 & $48.17(7.3)$ \\
Femininity & $49.42(8.1)$ & $51.11(8.1)$ & $n s$ & $49.92(8.1)$ \\
Peer Pressure & $27.96(9.8)$ & $32.93(9.9)$ & .001 & $29.42(10.0)$ \\
\hline
\end{tabular}

Note. All means were statistically tested while controlling for age.

differences in age or educational level between the online and offline respondents.

Table 1 summarizes the mean scores for homosexual and heterosexual respondents on the relevant variables. Homosexual men had a significantly lower Body Mass Index $\left(B M I=\mathrm{kg} / \mathrm{m}^{2}\right)$ than heterosexuals. Also, homosexual men scored higher on all EDE subscales and the EDE global scale, and scored higher on body dissatisfaction and peer pressure. Self-esteem was significantly lower among homosexual men compared to heterosexual men. Furthermore, heterosexual men scored higher on masculinity, while femininity did not differ between the two groups.

Table 2 provides the simple correlations between all scales used in the analyses for homosexual and heterosexual men. For homosexual men most scales were inter-correlated significantly with the exceptions of femininity on the one hand and eating disorder symptoms, body dissatisfaction, and self-esteem on the other hand. Masculinity on the one hand and eating disorder symptoms and peer pressure on the other hand were also not significantly correlated. For heterosexual men the pattern was somewhat different, as peer pressure was uncorrelated with eating disorder symptoms and self-esteem, masculinity and femininity were uncorrelated with eating disorder symptoms and body dissatisfaction, and femininity was not correlated with peer pressure. All other correlations were significant.

It was first hypothesized that increased body dissatisfaction and decreased self-esteem are related to increased levels of eating disorder 


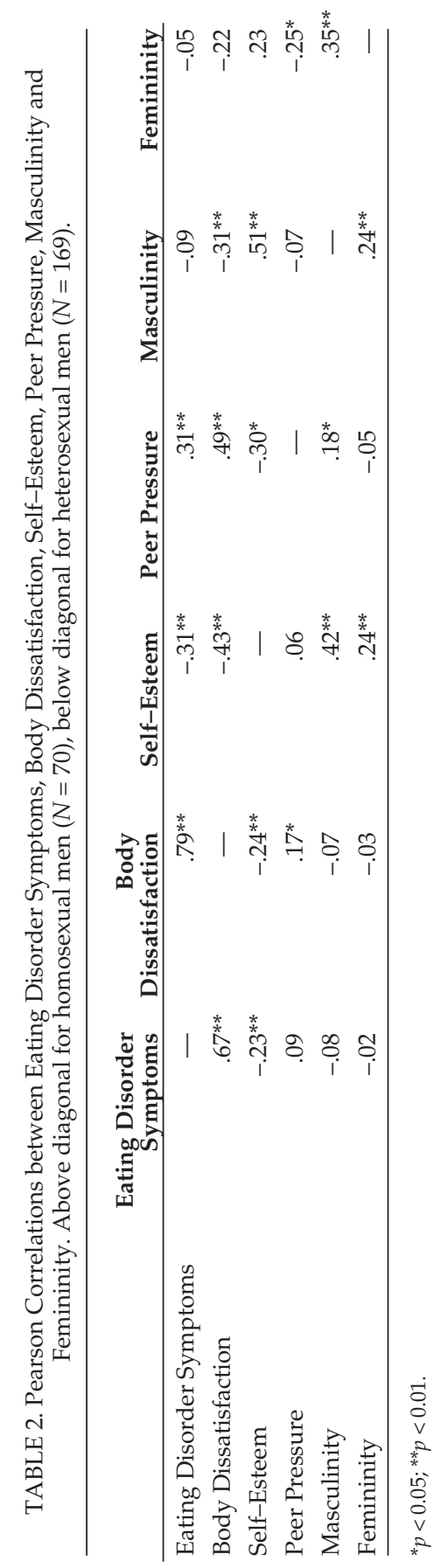

1194 
symptoms. The simple correlation between body dissatisfaction and eating disorder symptoms was .76, indicating that higher eating disorder scores are strongly related to higher body dissatisfaction. The simple correlation between self-esteem and eating disorder symptoms was -.33 , implying that higher eating disorder scores are related to lower self-esteem. Furthermore, using multiple regression analysis, the multivariate effects of self-esteem and body dissatisfaction on eating disorder symptoms were investigated (controlling for age). Body dissatisfaction was highly related $(\beta=.76, p<.001)$, while the contribution of self-esteem was non-significant ( $\beta=-.02$, ns). Since it may be argued that there is considerable overlap between body dissatisfaction and the EDE-Q subscales weight concerns and shape concerns, the analysis was rerun using only the mean score of the restraint and eating concerns subscales as dependent variable in the regression analysis. This resulted in a lower-but still highly significant-effect of body dissatisfaction ( $\beta$ $=.64, p<.001)$ and a non-significant effect of self-esteem $(\beta=-.01, n s)$.

The second hypothesis predicts that self-esteem and body dissatisfaction are dependent upon peer pressure and gender role orientation, and that these relationships were more pronounced in homosexual men. Given that the primary focus of this research was on eating disorders and that the multivariate regression analysis described above showed no relation between self-esteem and eating disorder symptoms, this hypothesis was tested only for body dissatisfaction. In a hierarchical multiple regression analysis with body dissatisfaction as the dependent variable, age and BMI were entered first; sexual orientation, femininity, masculinity, and peer pressure were entered in the second block; while the interaction terms of sexual orientation on the one hand and femininity, masculinity, and peer pressure on the other hand were entered in the final block.

The results of this regression analysis first showed that a homosexual orientation, lower masculinity scores, and more peer pressure were significantly related to more body dissatisfaction (see Table 3).

Furthermore, the interactional analysis yielded a significant result for peer pressure, showing the more pronounced effect of peer pressure on body dissatisfaction for homosexual men. Therefore, separate regression analyses were conducted for homosexual and heterosexual men. These stratified analyses showed that BMI was a strong predictor of body dissatisfaction for both heterosexuals and homosexuals ( $\beta \mathrm{s} .46$ and .37 respectively). Furthermore, for both heterosexual men and homosexual men lower masculinity and more peer pressure was related to more body dissatisfaction, and that the relationship between peer pressure and body dissatisfaction was substantially stronger for homosexual men $(\beta=.45)$, compared to heterosexual men $(\beta=.21)$. The proportion of 
TABLE 3. Multiple regression analyses with Body Dissatisfaction as dependent variable for the whole sample (top of table), and stratified for heterosexual and homosexual men (bottom of table).

\begin{tabular}{|c|c|c|c|c|c|c|c|}
\hline & $\beta$ & $t$ & $p<$ & $R^{2}$ & $\begin{array}{r}R^{2} \\
\text { hange }\end{array}$ & $\begin{array}{r}F \\
\text { hange }\end{array}$ & $p$ \\
\hline \multicolumn{8}{|l|}{ Whole sample } \\
\hline \multicolumn{8}{|l|}{ Block 1} \\
\hline Age & 0.07 & 1.1 & ns & & & & \\
\hline BMI & 0.28 & 4.5 & 0.001 & 0.09 & 0.09 & 11.6 & 0.001 \\
\hline \multicolumn{8}{|l|}{ Block 2} \\
\hline Sexual Orientation $^{1}$ & 0.33 & 5.9 & 0.001 & & & & \\
\hline Femininity & 0.01 & 0.2 & ns & & & & \\
\hline Masculinity & -0.27 & -4.9 & 0.001 & & & & \\
\hline Peer Pressure & 0.31 & 5.7 & 0.001 & 0.41 & 0.32 & 31.1 & 0.001 \\
\hline \multicolumn{8}{|l|}{ Block 3} \\
\hline Sexual Orientation $\times$ Femininity & 0.03 & 0.4 & $n s$ & & & & \\
\hline Sexual Orientation $\times$ Masculinity & -0.12 & -1.8 & ns & & & & \\
\hline Sexual Orientation $\times$ Peer & 0.25 & 4.0 & 0.001 & 0.46 & 0.05 & 6.1 & 0.001 \\
\hline \multicolumn{8}{|l|}{ Heterosexual Men } \\
\hline \multicolumn{8}{|l|}{ Block 1} \\
\hline Age & -0.08 & -1.1 & $n s$ & & & & \\
\hline BMI & 0.46 & 6.6 & 0.001 & 0.21 & 0.21 & 21.7 & 0.001 \\
\hline \multicolumn{8}{|l|}{ Block 2} \\
\hline Femininity & 0.01 & 0.2 & ns & & & & \\
\hline Masculinity & -0.22 & -3.1 & 0.01 & & & & \\
\hline Peer Pressure & 0.21 & 2.9 & 0.01 & 0.28 & 0.07 & 5.2 & 0.01 \\
\hline \multicolumn{8}{|l|}{ Homosexual Men } \\
\hline \multicolumn{8}{|l|}{ Block 1} \\
\hline Age & 0.05 & 0.4 & $n s$ & & & & \\
\hline BMI & 0.37 & 3.1 & 0.01 & 0.15 & 0.15 & 5.7 & 0.01 \\
\hline \multicolumn{8}{|l|}{ Block 2} \\
\hline Femininity & 0.06 & 0.5 & ns & & & & \\
\hline Masculinity & -0.31 & -3.1 & 0.01 & & & & \\
\hline Peer Pressure & 0.45 & 4.5 & 0.001 & 0.44 & 0.29 & 10.7 & 0.001 \\
\hline
\end{tabular}

$1_{0}=$ Heterosexual, $1=$ Homosexual

explained variance of the model was substantially higher for homosexual men compared to heterosexual men ( $44 \%$ versus $28 \%$ ). See the bottom part of Table 3 for details.

Finally, to test the third hypothesis, a hierarchical regression analysis was performed to investigate the relationship between sexual orientation, peer pressure, and gender role orientation on the one hand, and eating disorder symptoms on the other hand, while controlling for the contribution of self-esteem and body dissatisfaction in the prediction of eating disorder symptoms. 
TABLE 4. Multiple regression analyses with Eating Disorder Symptoms as dependent variable and (1) Sexual Orientation, Femininity, Masculinity, and Peer Pressure as predictors, and (2) Sexual Orientation, Femininity, Masculinity, and Peer Pressure as predictors after controlling for Self-Esteem and Body Dissatisfaction (in both analyses controlling for age and BMI)

\begin{tabular}{|c|c|c|c|}
\hline & $\beta$ & $t$ & $p<$ \\
\hline \multicolumn{4}{|l|}{ Direct } \\
\hline Sexual orientation ${ }^{1}$ & -0.24 & -3.6 & 0.001 \\
\hline Femininity & 0.01 & 0.2 & ns \\
\hline Masculinity & -0.09 & -1.3 & ns \\
\hline Peer Pressure & 0.15 & 2.4 & 0.05 \\
\hline \multicolumn{4}{|c|}{ Controlling for self-esteem and body dissatisfaction } \\
\hline Sexual orientation ${ }^{1}$ & -0.01 & -0.2 & $n s$ \\
\hline Femininity & 0.01 & 0.2 & $n s$ \\
\hline Masculinity & 0.12 & 2 & ns \\
\hline Peer Pressure & -0.05 & -0.9 & $n s$ \\
\hline
\end{tabular}

${ }_{0}=$ Heterosexual, 1 = Homosexual

This analysis revealed no significant effects (see Table 4), while a regression analysis that investigated the direct associations between sexual orientation, peer pressure and gender role orientation on the one hand, and eating disorder symptoms on the other hand showed that sexual orientation and peer pressure were significantly related to eating disorder symptoms (Table 4). These analyses indicate that sexual orientation and peer pressure are only indirectly related to eating disorder symptoms, through body dissatisfaction and self-esteem.

\section{DISCUSSION}

The present findings show that eating disorder symptoms are strongly related to body dissatisfaction and, contrary to part of the hypothesis, not by the level of self-esteem. Body dissatisfaction turned out to be strongly associated with BMI, peer pressure, especially among homosexuals, and to a lesser extent with masculinity scores. As hypothesized, when controlling for body dissatisfaction and self-esteem, no significant associations between sexual orientation, gender role orientation, peer pressure on the one hand and eating disorder symptoms on the other hand, were found.

These results exemplify the central role of body dissatisfaction in eating disorders. In addition, although many studies show bivariate corre- 
lations between self-esteem and eating disorder symptoms, which was replicated in the current study, the multivariate analysis showed that this relation is mediated by body dissatisfaction. Furthermore, whereas other studies have reported associations between eating disorder symptoms on the one hand and sexual orientation, gender orientation and peer pressure on the other hand, our multivariate analysis revealed that these effects become non-significant when taking body dissatisfaction into account. This once more illustrates the important role of body dissatisfaction in explaining eating disorders (cf. Stice, 2002).

Furthermore, the results showed that for both heterosexual and homosexual men, a higher level of body dissatisfaction was related to higher BMI, more peer pressure, lower masculinity scores, and to the interaction of sexual orientation and peer pressure. The investigation of this interaction revealed that the relationship between peer pressure and body dissatisfaction was substantially more pronounced among homosexual men. Body dissatisfaction was unrelated to femininity.

Whereas for heterosexual males body dissatisfaction seems to be to a greater extent dependent upon the more objective measure of BMI, for homosexual men perceptions of peer pressure appear to be of greater importance. This confirms findings from previous studies that have described the higher value within the gay community that is placed upon physical attractiveness (Williamson, 1999; Yelland \& Tiggemann, 2003). Considering the disproportional risk of homosexual men to develop an eating disorder, more research is warranted into the precise relationship between peer pressure, body dissatisfaction, and eating disorders for this risk group. More specifically, it may be worthwhile to investigate more in-depth which sources of peer pressure in the gay community can be identified, and how these pressures are received, processed, and acted upon by homosexual men.

Masculinity as well as femininity were unrelated to eating disorder symptoms, which contradicts the results from studies that identified masculinity as a protective factor and femininity as a risk factor (but in line with Russell \& Keel, 2002). However, masculinity was significantly related to lower body dissatisfaction. Masculinity has primarily been investigated in relation to eating disorders, and less in relation to body dissatisfaction, and more research is needed to clarify the precise nature of the relationship. Given the high correlations we found between masculinity and self-esteem for both homosexual and heterosexual men, it may be that masculine men are less prone to negative self-evaluation of their physical composure.

The present study has a number of limitations. First, due to the cross-sectional nature of the study caution is warranted with respect to the causality of the relationships that were described. Second, it should 
be noted that although the homosexual respondents scored significantly higher on eating disorder symptoms, the scores of all but a few respondents fell in the normal range. Third, not all the scales we used have been validated with males or, more specifically, with homosexual men. Fourth, the number of homosexual men in our study was limited, which made it difficult to conduct subgroup analyses regarding vulnerability to body dissatisfaction. Therefore, a replication of this study among a larger sample of homosexual men that would allow for subgroup analyses would be highly informative.

Notwithstanding these limitations, we believe the current study has provided more insight in possible precursors of eating disorders, and has highlighted the central role of body dissatisfaction. Furthermore, the results can be an input for further study to gain a better understanding of the overrepresentation of homosexual males among males with eating disorders.

\section{APPENDIX 1. PEER PRESSURE SCALE (PPS)}

Each question is scored on a 7-point scale ranging from $1=$ completely disagree to $7=$ completely agree. The global PPS-score is the sum of the nine items.

1. my friends consider physical appearance to be very important

2. my body ideal is influenced by the media

3. my friends dress according to the latest fashion

4. my friends take example by people in the media

5. my friends mind their weight

6. my friends criticize the appearance of others

7. my friends disapprove of others because of their appearance

8. my friends think it is important to be slender

9. my friends think it is important to be muscular

In this study $(N=239)$ the following scale properties were found: Cronbach's $\alpha$ was 0.84 . The theoretical range of the global PPS is 7 to 63 . In this study the scores ranged from 9 to 61 . The mean PPS-score was 29.42 . 


\section{REFERENCES}

Andersen, A.E. (1999). Eating disorders in gay males. Psychiatric Annals, 29, 206-212.

Bem, S.L. (1974). The measurement of psychological androgyny. Journal of Consulting and Clinical Psychology, 42, 155-162.

Boroughs, M., \& Thompson, J.K. (2002). Exercise status and sexual orientation as moderators of body image disturbance and eating in males. International Journal of Eating Disorders, 31, 307-311.

Brand, P.A., Rothblum, E.D., \& Solomon, L.J. (1992). A comparison of lesbians, gay men, and heterosexuals on weight and restrained eating. International Journal of Eating Disorders, 11, 253-259.

Cervera, S., Lahortiga, F., Martínez-González, M.A., Gual, P., de Irala-Estévez, J., \& Alonso, Y. (2003). Neuroticism and low self-esteem as risk factors for incident eating disorders in a prospective cohort study. International Journal of Eating Disorders, 33, 271-280.

Chung, Y.B. (1996). The construct validity of the Bem Sex-Role Inventory for heterosexual and gay men. Journal of Homosexuality, 30, 87-97.

Cooper, P.J., Taylor, M.J., Cooper, Z., \& Fairburn, C.G. (1987). The development and validation of the Body Shape Questionnaire (BSQ). International Journal of Eating Disorders, 6, 485-494.

Evans, C., \& Dolan, B. (1993). Body Shape Questionnaire: Derivation of shortened "alternative forms." International Journal of Eating Disorders, 13, 315-321.

Fairburn, C.G., \& Beglin, S.J. (1994). The assessment of eating disorders: Interview or self-report questionnaire? International Journal of Eating Disorders, 16, 363-370.

Gual, P., Pérez-Gaspar, M., Martínez-González, M.A., Lahortiga, F., de Irala-Estévez, J., \& Cervera-Enguix, S. (2002). Self-esteem, personality, and eating disorders: Baseline assessment of a prospective population-based cohort. International Journal of Eating Disorders, 31, 261-273.

Harvey, J.A., \& Robinson, J.D. (2003). Eating disorders in men: Current considerations. Journal of Clinical Psychology in Medical Settings, 10, 297-306.

Kalarchian, M.A., Wilson, G.T., Brolin, R.E., \& Bradley, L. (2000). Assessment of eating disorders in bariatric surgery candidates: Self-report questionnaire versus interview. International Journal of Eating Disorders, 28, 465-469.

Lakkis, J., Ricciardelli, L.A., \& Williams,R.J. (1999). Role of sexual orientation and gender-related traits in disordered eating. Sex Roles, 41, 1-16.

Meyer, C., Blissett, J., \& Oldfield, C. (2001). Sexual orientation and eating psychopathology: The role of masculinity and femininity. International Journal of Eating Disorders, 29, 314-318.

Moore, F., \& Keel, P.K. (2002). Influence of sexual orientation and age on disordered eating attitudes and behaviors in women. International Journal of Eating Disorders, 34, 370-374.

Murnen, S.K., \& Smolak, L. (1997). Femininity, masculinity, and disordered eating: A meta-analytic review. International Journal of Eating Disorders, 22, 231-242.

Rosenberg, M. (1965). Society and the adolescent self-image. Princeton, NJ: Princeton University Press.

Russell, C.J., \& Keel, P.K. (2002). Homosexuality as a specific risk factor for eating disorders in men. International Journal of Eating Disorders, 31, 300-306.

Stice, E. (2002). Risk and maintenance factors for eating pathology: A meta-analytic review. Psychological Bulletin, 128, 825-848. 
Stice, E., Maxfield, J., \& Wells, T. (2003). Adverse effects of social pressure to be thin on young women: An experimental investigation of the effects of "fat talk." International Journal of Eating Disorders, 34, 108-117.

Stice E., \& Shaw, H.E. (2002). Role of body dissatisfaction in the onset and maintenance of eating pathology. A synthesis of research findings. Journal of Psychosomatic Research, 53, 985-993.

Strong, S.M., Singh, D., \& Randall, P.K. (2000). Childhood gender nonconformity and body dissatisfaction in gay and heterosexual men. Sex Roles, 43, 427-439.

Strong, S.M., Williamson, D.A., Netemeyer, R.G., \& Geer, J.H. (2000). Eating disorder symptoms and concerns about body differ as a function of gender and sexual orientation. Journal of Social and Clinical Psychology, 19, 240-255.

Wilfley, D.E., Schwartz, M.B., Spurrell, E.B., \& Fairburn, C.G. (1997). Assessing the specific psychopathology of binge eating disorder patients: Interview or self-report? Behaviour Research and Therapy, 35, 1151-1159.

Williamson, I. (1999). Why are gay men a high risk group for eating disturbance? European Eating Disorders Review, 7, 1-4.

Williamson, I., \& Hartley, P. (1998). British research into the increased vulnerability of young gay men to eating disturbance and body dissatisfaction. European Eating Disorders Review, 6, 160-170.

Yelland, C., \& Tiggemann, M. (2003). Muscularity and the gay ideal: Body dissatisfaction and disordered eating in homosexual men. Eating Behaviors, 4, 107-116. 